\title{
Genes encoding xylan and $\beta$-glucan hydrolysing enzymes in Bacillus subtilis: characterization, mapping and construction of strains deficient in lichenase, cellulase and xylanase
}

\author{
Monika Wolf, Attila Geczi, Ortwin Simon and Rainer Borriss
}

Institut für Biologie, Humboldt Universităt Warschauer Straße 43, D-10248, Berlin, Germany

\author{
Author for correspondence: Rainer Borriss. Tel: +4930 5894158. Fax +49305888807. \\ e-mail: h0135nax@biologie.hu-berlin.de
}

Keywords: Bacillus subtilis, genome sequencing, gene mapping, xylanase, cellulase, lichenase

\section{INTRODUCTION}

Cellulose (insoluble fibres of $\beta$-1,4-glucan) and hemicellulose (non-cellulosic polysaccharides including glucans, mannans and xylans) are the major constituents of plant cell walls. $\beta-1,4-X y l a n s$ are mainly found in secondary cell walls of plants, the major component of woody tissue (Thomson, 1993). The mixed linked 1,3-1,4$\beta$-glucans form the major part of cell walls of cereals like oat and barley. The aerobic soil bacterium Bacillus subtilis secretes different hydrolases enabling this organism to use external cellulosic and hemicellulosic substrates. Three types of $\beta$-glucan endohydrolase able to degrade $1,3-1,4-$ $\beta$-glucans but distinguished by fine differences in substrate specificity are known. Two of them, endo-1,4$\beta$-glucanase or carboxymethylcellulase (CMCase, cellulase, EC 3.2.1.4) and endo-1,3-1,4- $\beta$-glucanase or lichenase (EC 3.2.1.73) are secreted by $B$. subtilis. The third $\beta$-glucan endohydrolase (endo-1,3(4)- $\beta$-glucanase, EC 3.2.1.6) able to hydrolyse laminarin and barley glucan was detected only in Rbizopus arrbizus (Anderson

\footnotetext{
Abbreviations: $\mathrm{AZCL}$, Azurine-Crosslinked; $\mathrm{CMCase,} \mathrm{carboxymethylcellu-}$ lase; MUG, 4-methylumbelliferyl- $\beta$-D-galactopyranoside.

The EMBL accession numbers for the nucleotide sequences reported in this paper are Z46862 (bg), Z29076 (egl) and Z34519 (xynA1).
}

\& Stone, 1975). Lichenase encoded by the bglS gene is restricted in its substrate range to mixed linked $\beta$-glucans. Only 1,4-linkages adjacent to 1,3 -linkages are hydrolysed. CMCase encoded by the eglS gene cleaves carboxymethylcellulose (CM-cellulose) and 1,3-1,4$\beta$-glucans by hydrolysing internal $1,4-\beta$-linkages next to 1,4-linked glucose residues (Anderson \& Stone, 1975). Endo-1,4- $\beta$-xylanase (xylanase, $1,4-\beta$-xylan xylanohydrolase, EC 3.2.1.8), encoded by the $x y n A$ gene, is a component of the complex spectrum of different activities produced by B. subtilis to break down plant cell walls (Takahashi \& Hashimoto, 1963).

The $b g l S$ and $e g l S$ genes have been isolated from industrial $B$. subtilis strains and the amino acid sequences of their products have been deduced (Murphy et al., 1984; MacKay et al., 1986). Despite related substrate specificity, the two gene products do not show any similarity at the level of primary sequence and they belong to different families of $\beta$-glucan hydrolases. The structure of the $x y n A$ gene cloned from $B$. subtilis PAP115 has also been reported. Amino acid sequences deduced from the coding region of the $x y n A$ genes isolated from $B$. subtilis and $B$. pumilus share more than $50 \%$ identity (Paice et al., 1986). Unfortunately, the eglS, bglS and xyn $A$ genes of $B$. subtilis 168 have not been structurally characterized.

The bglS gene has been mapped by PBS1 transduction in 
the sac $A$-pur $A$ region of the $B$. subtilis chromosome and is closely linked to the but locus (O'Kane et al., 1985; Borriss et al., 1986). An ORF, designated $b g l T$, precedes the $b g l S$ gene. The $b g l T$ gene product shares striking similarity with anti-terminator proteins such as those encoded by Eschericbia coli bglG, and B. subtilis sac $Y$ and sac T genes (Lindner et al., 1993). The position of egl on the B. subtilis chromosome is not known. Strains harbouring mutations within the $b g l$ gene retain about $5-10 \%$ of wild-type activity against 1,3-1,4- $\beta$-glucan, suggesting that enzymes other than the $b g l$ gene product might be involved in degrading mixed linked $\beta$-glucans (Borriss et al., 1986).

$x y n A$ and $x y n B$ mutants (deficient in extracellular xylanase and cell-bound $\beta$-xylosidase, respectively) unable to use xylan as sole carbon source were mapped at $48^{\circ}$ on the $B$. subtilis chromosome (Roncero, 1983). The $x y n B$ and $x y l$ genes of the xylose regulon are clustered in a $7.5 \mathrm{~kb}$ segment of the chromosome of $B$. subtilis 168 (Hastrup, 1988). Azevedo et al. (1993) mapped $x y l$ at about $173^{\circ}$ by probing with a YAC library. Studies by S. A. Zahler, cited by Azevedo et al. (1993), also indicate that the xylose regulon maps near thy $A\left(168^{\circ}\right)$ and $c i t B\left(173^{\circ}\right)$. Therefore, we must assume that the $x y n A$ locus is in fact far away from the clustered $x y n C-x y n B$ and $x y l A-x y l B$ operons or the mapping data for $x y n A$ need to be corrected.

To analyse degradation of cellulose and hemicelluloses by B. subtilis strain 168, xyn $A, b g l S$ and eglS were cloned and characterized. The genes encoding extracellular hemicellulases and cellulase are not clustered but rather map at different sites on the chromosome. $\mathrm{Egl}^{-} \mathrm{Bgl}^{-}$double mutants, constructed in this study, suggest that only the bglS and eglS gene products are involved in $\beta$-glucan degradation in $B$. subtilis. The $\beta$-glucanase-negative strains might be used to study expression of genes cloned from other Gram-positives.

\section{METHODS}

Bacterial strains and plasmids. A list of Bacillus subtilis strains and plasmids used in this study is given in Table 1.

Detection of extracellular endo- $\beta$-glucanases and xylanases. For the detection of enzyme activity on plates, LB agar was supplemented with $0.05 \%$ lichenan, $0.2 \%$ cellulose, and $0.7 \%$ oat xylan. After growth at $37^{\circ} \mathrm{C}$, plates were stained by flooding with $0.1 \%$ Congo red: clear haloes around colonies are indicative of $\beta$-glucanase activity. Improved clear zones were obtained by treatment of stained agar plates with $1 \mathrm{M} \mathrm{NaCl}$. Agar plates containing Azurine-Crosslinked (AZCL) polysaccharides (Megazyme) were prepared by adding $0.2 \%$ of the substrate to LB agar. Extracellular enzyme activity was indicated by liquefaction of the substrate particles around the colonies.

Cellular fractions of $E$. coli transformed by recombinant plasmids and supernatants of various $B$. subtilis strains were subjected to activity staining of endo- $\beta$-glucanases after SDSPAGE. The fractionation of extracellular, periplasmic and cytoplasmic endoglucanases was carried out by the method of Cornelis (Cornelis et al., 1982). SDS-PAGE was done in $15 \%$ $(\mathrm{w} / \mathrm{v})$ acrylamide gel. Zymograms were prepared using $0.5 \%$ CM-cellulose, $0.5 \%$ oat spelt xylan, and $0.3 \%$ lichenan that had been copolymerized with polyacrylamide. After running, SDS was removed by repeated washing with ethanol/water $(1: 1$, $\mathrm{v} / \mathrm{v}$ ). The gels were equilibrated in $50 \mathrm{mM}$ sodium acetate buffer, $\mathrm{pH} 6.0$, incubated for $1 \mathrm{~h}$ at $37^{\circ} \mathrm{C}$, and stained with $0.5 \%$ Congo red. Clear zones were improved with $0.5 \mathrm{M} \mathrm{NaCl}$ in $10 \mathrm{mM}$ Tris/ $\mathrm{HCl}, \mathrm{pH} 8$.

Assays for $V_{\max }$ were performed with purified protein samples

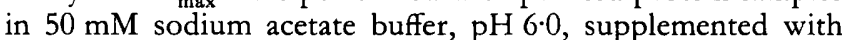
$10 \mathrm{mM} \mathrm{CaCl}_{2}$ as described by Olsen et al. (1991). Lichenan $(2.0 \%, \mathrm{w} / \mathrm{v}), \mathrm{CM}$-cellulose $(0.5 \%)$, oat spelt and birch wood xylan $(0.5 \%)$ were used as substrates. One unit of enzyme activity is defined as the amount of enzyme producing $1 \mu \mathrm{mol}$ reducing sugar (as glucose equivalents) per minute. Alternatively, enzyme activity was measured using AZCL barley $\beta$ glucan, AZCL HE-cellulose, and AZCL xylan from oat spelts as substrate. AZCL polysaccharide $(5 \mathrm{mg})$ in $20 \mathrm{mM}$ sodium acetate buffer, $\mathrm{pH} 6.0$, supplemented with $10 \mathrm{mM} \mathrm{CaCl}_{2}$ and $50 \mu \mathrm{g}$ bovine serum albumin was shaken with the enzyme for $20 \mathrm{~min}$ at $50{ }^{\circ} \mathrm{C}$. To stop the reaction, $2 \mathrm{ml}$ ethanol was added and the optical density was measured at $595 \mathrm{~nm}$. One unit was defined as the amount of enzyme giving an $\mathrm{OD}_{595}$ of $1.0 \mathrm{~min}^{-1}$.

Detection of $\boldsymbol{\beta}$-galactosidase. When $\beta$-galactosidase $\alpha$-complementation was assayed, either X-Gal $\left(60 \mu \mathrm{g} \mathrm{ml}^{-1}\right)$ or the fluorogenic substrate 4-methylumbelliferyl- $\beta$-D-galactopyranoside (MUG) was used. MUG (10 $\mathrm{mg} \mathrm{m}^{-1}$ in DMSO) was sprayed onto plates after colonies had formed. Fluorescence produced by hydrolysis of MUG reflects the actual activity of $\beta$ galactosidase present in bacteria.

Cloning and sequencing of the egl and bgl genes. Clones harbouring the $b g l S$ and $e g l S$ genes were isolated from a genomic library of $B$. subtilis 168 cloned in phage $\lambda$ L47.1 (Putzer et al., $1990)$. DNA from phage clones exhibited $\beta$-glucan hydrolysing activity was isolated, digested by HindIII and subcloned into vector pBR322 (Bolivar et al., 1977). Clones hydrolysing CMcellulose $(e g / S)$ and lichenan (bglS) were selected. Isolated plasmids were shown to direct expression of eglS (pRB36) and bglS (pRB31). Another approach to isolating genes encoding $\beta$ glucan hydrolases used vector plasmid pBR322. Chromosomal DNA isolated from B. subtilis 168 was partially digested by SauIIIA and size-fractionated by agarose gel electrophoresis. DNA fragments of $2-10 \mathrm{~kb}$ in size were ligated into pBR322 linearized by BamHI and dephosphorylated by alkaline phosphatase. E. coli $\mathrm{DH} 5 \alpha$ cells transformed with the ligation mixture were screened for CMCase activity as described above. Plasmid pAG1 directs synthesis of B. subtilis cellulase in E. coli.

DNA sequencing was done by dideoxy-chain termination reactions (Sanger et al., 1977). Fragments from plasmds pAG1 and pRB36 were created by using convenient restriction sites and subcloned into the appropriately digested and dephosphorylated vectors pTZ19R and pTZ18R (Mead et al., 1986). Double-stranded recombinant plasmid DNAs were used as templates.

Amplification and sequencing of the $x y n A$ gene. $x y n A$ specific DNA was amplified by PCR from $B$. subtilis 168 chromosomal DNA. DNA from B. subtilis 168 was prepared by the method of Saito \& Miura (1963). Reaction mixtures of $50 \mu \mathrm{l}$ contained $100 \mathrm{ng}$ PvuII-cleaved DNA, $50 \mathrm{pmol}$ of each oligonucleotide primer, $25 \mathrm{mM}$ Tris $/ \mathrm{HCl}, \mathrm{pH} 8.5,50 \mathrm{mM} \mathrm{KCl}$, $3 \mathrm{mM} \mathrm{MgCl}, 0.5 \mathrm{mM}$ of each nucleoside triphosphate (NTP) and $2 \mathrm{U}$ Taq polymerase. The sequences of the primers were deduced from the published sequence of the $B$. subtilis PAP115 xynA gene (Lindner et al., 1994): xynA/oli1, 5' CTGAATTCGTGGTAT'TATACTGAAGG; xynA/oli2, 5' CCTGATTAAGGAAGATCTGT'TACC. The restriction sites for EcoRI (xynA/oli1) and $B g l \mathrm{II}$ (xynA/oli2) within the primer sequence are underlined. Template DNA was denatured at $94{ }^{\circ} \mathrm{C}$ for $1 \mathrm{~min}$, annealed at $55^{\circ} \mathrm{C}$ for $1 \mathrm{~min}$ and extended for $2 \mathrm{~min}$ at $72^{\circ} \mathrm{C}$ for 30 cycles. The $770 \mathrm{bp}$ PCR product was 
Table 1. Strains and plasmids

\begin{tabular}{|c|c|c|}
\hline Strain/plasmid & Characteristics & Source/reference \\
\hline \multicolumn{3}{|l|}{ B. subtilis } \\
\hline 168 & $\operatorname{trp} C 2$ & BGSC, Ohio, USA \\
\hline 6GM15 & $\operatorname{trp} C 2$ tyr met bis ura rib $\left(\mathrm{r}_{\mathrm{M}}^{-} \mathrm{m}_{\mathrm{M}}^{+}\right)$lacZ $\Delta \mathrm{M} 15 \mathrm{Km}^{\mathrm{R}}$ & Haima et al. (1990) \\
\hline DB104 & bis nprR2 nprE18 $\triangle a p r A 3$ & Kawamura \& Doi (1984) \\
\hline MW8 & bis nprR2 nprE18 $\triangle a p r A 3 \Delta e g l S 102$ & This work \\
\hline MW9 & 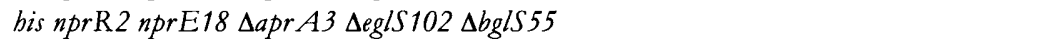 & This work \\
\hline MW10 & bis nprR2 nprE18 $\Delta a p r A 3 \Delta$ sglS102 $\Delta$ bglT bglSR $V$ & This work \\
\hline MW11 & 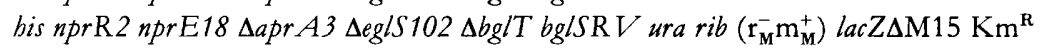 & This work \\
\hline MW12 & $\begin{array}{l}\text { bis } n p r \mathrm{R} 2 n \operatorname{np} E 18 \Delta a p r A 3 \Delta \text { eglS102 } \Delta \text { bglT bglSR V trpC2 ura rib }\left(\mathrm{r}_{\mathrm{M}}^{-} \mathrm{m}_{\mathrm{M}}^{+}\right) \\
\text {lacZ } \mathrm{M} 15 \mathrm{Km}^{\mathrm{R}}\end{array}$ & This work \\
\hline MW13 & $\begin{array}{l}\text { bis nprR2 } n p r E 18 \Delta a p r A 3 \Delta e g l S 102 \Delta b g l T \text { bglSR } V \text { trpC2 tyr ura rib }\left(\mathrm{r}_{\mathrm{M}}^{-} \mathrm{m}_{\mathrm{M}}^{+}\right) \\
\text {lacZ } \Delta \mathrm{M} 15 \mathrm{Km}^{\mathrm{R}}\end{array}$ & This work \\
\hline MW14 & bis nprR2 nprE18 $\triangle a p r A 3 \Delta$ bglS55 & This work \\
\hline MW15 & bis nprR2 nprE18 $\Delta a p r A 3 \Delta$ eglS102 $\Delta b g l T$ bglSR V $\Delta x y n A \mathrm{Cm}^{\mathrm{R}}$ & This work \\
\hline \multicolumn{3}{|l|}{ YACs } \\
\hline YAC $12-5$ & $130 \mathrm{~kb}$ YAC insert with thy $A x y l$ cit $B$ (map position $165^{\circ}$ ) & \multirow{3}{*}{$\begin{array}{l}\text { P. Serror, INRA, } \\
\text { Jouy-en-Josas, France }\end{array}$} \\
\hline YAC $15-37$ & $130 \mathrm{~kb}$ YAC insert with citB (map position $169^{\circ}$ ) & \\
\hline YAC $15-19$ & $175 \mathrm{~kb}$ YAC insert with glt $A \operatorname{ter} C$ odh $A\left(\right.$ map position $\left.173^{\circ}\right)$ & \\
\hline \multicolumn{3}{|l|}{ Plasmid } \\
\hline pHPS9 & $\mathrm{Cm}^{\mathrm{R}} \mathrm{Er}^{\mathrm{R}}$, cat-86: : lac $Z \alpha$, p'A $1060-\mathrm{pUC9}$ derivative & Haima et al. (1990) \\
\hline pRB31 & pBR322 containing a $5.6 \mathrm{~kb}$ HindIII fragment of $b g l$ of $B$. subtilis & This work \\
\hline pRB33 & pBR322 containing a $2.8 \mathrm{~kb}$ HindIII-SpbI fragment of bglS & This work \\
\hline pAG1 & pBR 322 containing a $3.6 \mathrm{~kb}$ fragment of egl of $B$. subtilis & This work \\
\hline pAG2 & pBR322 containing a $1.9 \mathrm{~kb}$ fragment of egl of B. subtilis & This work \\
\hline pRB36 & pBR322 containing a $2.8 \mathrm{~kb}$ HindIII of egl of B. subtilis & This work \\
\hline pRB37 & pUC19 containing a $2.8 \mathrm{~kb}$ HindIII of egl of B. subtilis & This work \\
\hline pHV60 & $\mathrm{Ap}^{\mathrm{R}} \mathrm{Tc}^{\mathrm{R}} \mathrm{Cm}^{\mathrm{R}}$, pBR322 derivative, cat gene from $\mathrm{pC} 194$ & Michel et al. (1983) \\
\hline pMW1 & pHV60 containing a $2 \cdot 8 \mathrm{~kb}$ HindIII-SphI fragment of pRB33 & This work \\
\hline pMW2 & pHV60 containing a $4.3 \mathrm{~kb}$ EcoRV-SalI fragment of pAG1 & This work \\
\hline pMW3 & pMW1 containing a $0.7 \mathrm{~kb}$ deletion within bgls & This work \\
\hline pMW4 & pMW 1 containing a $1 \cdot 2 \mathrm{~kb}$ deletion within the $b g l T-b g l S$ region & This work \\
\hline pMW5 & pMW 2 containing a $0.7 \mathrm{~kb}$ deletion within $e g / S$ & This work \\
\hline pMW6 & pBR322 containing 770 bp of $x y n A$ & This work \\
\hline pMW7 & pTZ18R containing $770 \mathrm{bp}$ of $x y n A$ & This work \\
\hline pMW8 & pHV60 containing an internal Pst $\mathrm{I}-S_{c a I}$ fragment of $x y n A$ & This work \\
\hline
\end{tabular}

digested with EcoRI and $B g / \mathrm{II}$. Electrophoresis was done in $1.2 \%$ agarose gels (SeaKem). The amplified DNA product was isolated and cloned into pTZ18R digested with appropriate restriction enzymes. The resulting recombinant plasmid directed xylanase synthesis in transformed E. coli DH5 $\alpha$ cells and was used for sequencing by the chain termination method (Sanger et al., 1977). To get sequence information for both strands, subfragments prepared by several restriction enzymes were used as templates for DNA sequencing.

Gene expression and purification of enzymes. E. coli $\mathrm{DH} 5 \alpha$ cells transformed with recombinant plasmids encoding xylanase (Xyn), lichenase $(\mathrm{Bgl})$ or CMCase (Egl) were grown in standard LB medium containing ampicillin $\left(100 \mu \mathrm{g} \mathrm{ml}^{-1}\right)$ for $20 \mathrm{~h} .1,3$ 1,4 -endo- $\beta$-glucanase in the periplasmic space was liberated by osmotic shock as described by Cornelis et al. (1982), resuspended in sodium acetate buffer, $\mathrm{pH} 5.0,10 \mathrm{mM} \mathrm{CaCl}_{2}$, and concentrated by ultrafiltration (Amicon). The sample was applied to a column containing CM-Sepharose CL-6B (Pharmacia) and eluted with a linear gradient of $0-400 \mathrm{mM} \mathrm{NaCl}$. Fractions containing lichenase were further purified by gel chromato- graphy using Sephacryl S-200 (Pharmacia) before analysis by SDS-PAGE. CMCase was purified in a similar way except that the enzyme was equilibrated against acetate buffer, $\mathrm{pH} 4 \cdot 5$, before loading onto a CM-Sepharose CL-6B column.

Xylanase was prepared from the supernatant by precipitating with ammonium sulfate $\left(60 \%\right.$ saturation) for $24 \mathrm{~h}$ at $4{ }^{\circ} \mathrm{C}$. The precipitate was resuspended and ultrafiltered twice against $0 \cdot 1 \mathrm{M}$ sodium acetate buffer, $\mathrm{pH}$ 5. FPLC chromatography with CMSepharose and Sephacryl S-200 was performed as described for $\beta$-glucanases.

Transformation and mapping procedures. E. coli cells were grown and prepared for transformation as described by Lederberg \& Cohen (1974) and competent B. subtilis cells were transformed as described previously (Borriss et al., 1986).

PBS1 transduction was performed with lysates from a set of $B$. subtilis strains containing transposon Tn917 insertions (Vandeyar \& Zahler, 1986). The recipient was the double mutant strain MW10 devoid of lichenase and cellulase activity. $\mathrm{Em}^{\mathbf{R}}$ transductants were scored for their ability to hydrolyse lichenan and CM-cellulose. To map the $e g l S$ gene more precisely, a lysate 
of PBS1 grown on MW10 was used to infect the reference strains $1 \mathrm{~A} 6$ (ilv A1 pyrD1 thy A1 thyB1 trpC2) and 1A7 (glt A292 $\operatorname{trpC2}$; Dedonder et al., 1977). Transductants were scored for their ability to hydrolyse $C M$-cellulose. $x y n A$ was mapped essentially in the same way except that strain MW15, devoid of xylanase, lichenase and cellulase activity, was the recipient. A PBS1 lysate made on MW15 was used to infect strains $1 \mathrm{~A} 6$ and 1A7. The ability of the transductants to hydrolyse AZCL xylan was scored.

Digoxigenin-labelled $x y n A, b g l S$ and $e g l S$ gene probes were used to hybridize an ordered collection of YAC clones containing more than $98 \%$ of the whole $B$. subtilis genome (Azevedo et al., 1993). A nylon membrane containing the whole set of YAC clones was prehybridized for $2 \mathrm{~h}$ at $42^{\circ} \mathrm{C}$ in hybridization solution, followd by hybridization with the probes overnight at $42{ }^{\circ} \mathrm{C}$ in the same solution. YAC clones hybridizing with $\mathrm{egl}$ and $b g l$ were detected after washing twice in $50 \%(\mathrm{v} / \mathrm{v})$ formamide, $0.1 \% \mathrm{SDS}, 0.36 \mathrm{M} \mathrm{NaCl}, 20 \mathrm{mM}$ sodium phosphate, $2 \mathrm{mM}$ EDT A for $20 \mathrm{~min}$ at $42^{\circ} \mathrm{C}$ and once in $18 \mathrm{mM} \mathrm{NaCl}, 0 \cdot 1 \%$ SDS for $20 \mathrm{~min}$ at $42{ }^{\circ} \mathrm{C}$. The isolation of YAC DNA used for Southern hybridization is described in the accompanying paper (Tam \& Borriss, 1995).

Strain deposition. Bacillus strains MW10 (1A751) and MW12 (1A752) have been deposited in the BGSC, Ohio, USA.

\section{RESULTS}

\section{Deletion of the $b g /$ gene}

To facilitate construction of strains with a deleted $b g / S$ gene, recombinant phages hydrolysing lichenan were isolated from a $\lambda 47.1$ library. A $5.6 \mathrm{~kb}$ HindIII DNA fragment isolated from $\lambda 47.1$-Lic1 directs lichenan-degrading activity. The fragment was cloned into pBR322. E. coli DH5 $\alpha$ cells transformed with the resulting plasmid pRB31 hydrolysed lichenan but were not active against CM-cellulose. Restriction enzyme analysis and hybridization with the $b g l S$ gene previously cloned from B. subtilis 168 (Borriss et al., 1986) revealed that the $5.6 \mathrm{~kb}$ fragment contains the bglS gene (Fig. 1a). The nucleotide sequence of the $b g l S$ gene was determined. The deduced amino acid sequence was found to be identical in 234 out of 242 residues with that reported for $B$. subtilis $\mathrm{C} 120$ (Murphy et al., 1984).

To construct an integration plasmid carrying a defective bglS gene, a $1.86 \mathrm{~kb}$ EcoRI-SphI fragment carrying the entire sequence of $b g l S$ was blunt-ended and cloned into the unique EcoRV site of vector pHV60. The resultant plasmid, pMW1, was linearized with EcoRV and treated with Bal31 exonuclease. Deletions of $400-900$ bp were obtained. After religation, plasmid pMW3, carrying a deletion within the $b g l S$ gene of about 700 bp ( $\Delta b g l S 55)$, was selected for further studies. Another deletion $(\Delta b g l T / b g l S R V)$ within the $2.8 \mathrm{~kb}$ HindIII/SpbI fragment was obtained by removing the $1.2 \mathrm{~kb} E c o \mathrm{RV}$ fragment containing the $3^{\prime}$ part of $b g l T$ and the $5^{\prime}$ half of $b g l S$ (Fig. 1a).

\section{Structure of the eg/S gene and biochemical properties of its product}

The eglS gene was cloned by screening the phage $\lambda 47.1$ library on agar plates containing $0.2 \% \mathrm{CM}$-cellulose (see Methods). Different DNA fragments expressing the eglS gene were subcloned into pBR322. Plasmids pAG1 and pRB36 contain overlapping DNA fragments (Fig. 1b). Restriction analysis indicated a high degree of similarity to a DNA fragment containing the endo- $1,4-\beta$-glucanase gene from $B$. subtilis PAP115. The nucleotide sequences of the eglS gene and its flanking regions were determined. Two ORFs were found within a stretch of $3500 \mathrm{bp}$. One of them, extending from 1380 to 2876 encodes a protein of 499 amino acid residues. The predicted protein with a molecular mass of $55287 \mathrm{Da}$ was very similar to those of other extracellular cellulases already cloned from other $B$. subtilis strains. In particular, the amino acid sequence of EglS was found to be identical to that of the eglS gene product of $B$. subtilis PAP115 but does not share any similarity with the $b g l S$ gene product.

The mature protein, lacking its signal peptide, consists of 470 amino acid residues with a molecular mass of $52264 \mathrm{Da}$. Several cellulase isoenzymes with apparent molecular masses ranging from $49 \mathrm{kDa}$ to $31.5 \mathrm{kDa}$ were detected in zymograms of $E$. coli strains transformed by eglS-bearing plasmids pRB37 and pAG2 (results not shown). The main activities detected on active gels containing lichenan and CM-cellulose were $35.5 \mathrm{kDa}$ and $33.5 \mathrm{kDa}$ in size (Fig. 4, lane 7). Processing or degradation of the primary translation product, in addition to signal peptide cleavage, has been reported for other endo-1,4- $\beta$ glucanases (Lo et al., 1988; Shima et al., 1993).

Biochemical studies performed with the purified product of the eglS gene revealed important differences in substrate specificity and $V_{\max }$ compared with the 1,3-1,4-endo- $\beta$ glucanase. The enzyme was able to degrade lichenan, $\mathrm{CM}$ cellulose and AZCL oat xylan. In contrast, the bglS gene product only hydrolysed lichenan but not CM-cellulose and xylan. However, specific activity towards the mixed linked 1,3-1,4- $\beta$-glucan was much higher in the 1,3-1,4endo- $\beta$-glucanase than in 1,4-endo- $\beta$-glucanase (Table 2).

A second but incomplete ORF, orf $X$, encoding more than 358 amino acid residues, was identified $5^{\prime}$ of eglS. The $\mathrm{N}$ terminal part of $\operatorname{orf} X$ is interrupted by the left-hand HindIII site of the fragment. The two ORFs are separated by a putative termination signal formed by an inverted repeat of $14 \mathrm{nt}$ at position $1095[\Delta G=-18.2 \mathrm{kcal}$ $(-76 \cdot 1 \mathrm{~kJ})]$.

To construct an integration plasmid carrying a defective eglS gene, we followed the strategy described for $b g l$. A DNA fragment carrying the eglS gene was recloned into pHV60, linearized by $M l u \mathrm{I}$, treated with Bal31 and religated. A clone with a 643 bp deletion within eglS ( $\Delta$ eglS102) was chosen for integration into the chromosome of B. subtilis (Fig. 1b).

\section{Cloning and properties of the xynA gene}

A 770 bp DNA fragment harbouring the entire $x y n A$ gene sequence was amplified from chromosomal DNA from B. subtilis 168 and recloned into vector plasmids pBR322(pMW6) and pTZ18R(pMW7). E. coli cells harbouring recombinant plasmids pMW6 or pMW7 conferred xylanase activity. The nucleotide sequence was found to be identical to that from B. subtilis PAP115 (Paice 
(a)

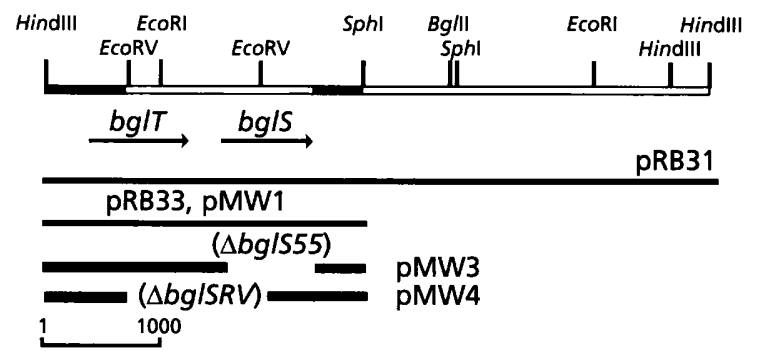

(b)

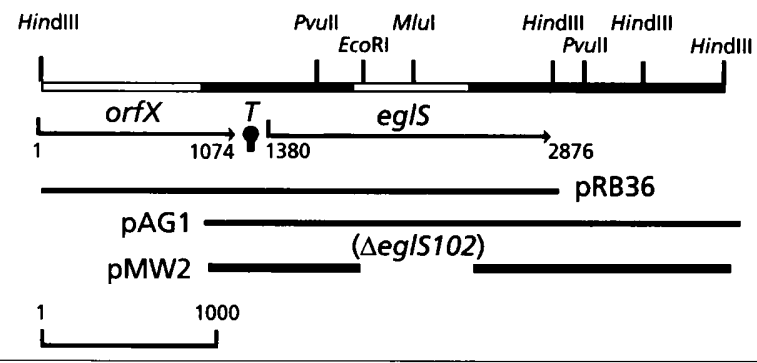

Fig. 1. Restriction map and deletion analysis of $\mathrm{bgl}$ and egl. (a) Restriction map of a $5.6 \mathrm{~kb}$ HindlII fragment harbouring $\mathrm{bg} / \mathrm{T}$ and $b g / S$. The ORFs of $b g / T$ and $b g / S$ are indicated by arrows. DNA fragments used to replace the chromosomal bgl genes are shown as filled boxes. The deleted regions $\triangle b g / S 55$ and $\triangle b g / S R V$ are indicated by Activity parentheses. + , detection of lichenase activity on lichenan agar plates. Plasmids pMW3 and PMW4 were used to delete chromosomal bgl genes in B. subtilis DB104.

$+\quad$ Sequence analysis of $\Delta b g / S 55$ revealed that $669 \mathrm{nt}$ out of a total of $726 \mathrm{nt}$ within the region encoding $b g / S$ have been deleted. (b) Restriction map of $B$. subtilis DNA harbouring an incomplete orfX (1-1074) and eg/S (1380-2876). The map was constructed on the basis of two overlapping DNA fragments cloned in plasmids pAG1 and pRB36. The sequenced region and the length of the ORFs are indicated. The Activity terminator-like sequence is labelled with a $T$. + , detection of cellulase activity on CMcellulose agar plates. Plasmid pMW2 $+\quad$ harbouring deletion $\Delta$ eg/S102 was used to - replace the eg/S gene. Sequence analysis of - $\Delta$ eg/S102 revealed that $643 \mathrm{nt}$ within the eg/S region encoding $E_{169}$ to $D_{385}$ have been deleted.
Table 2. Substrate specificities of endo-1,4- $\beta$-glucanase (Egl, 1,3-1,4- $\beta$-glucanase (Bgl) and 1,4- $\beta$-xylanase (XynA) purified to electrophoretic homogenity from $E$. coli cells harbouring recombinant plasmids pRB33 (bg/S), pRB37 (eg/S) and pMW7 (xynA)

Enzyme activities were calculated from the results of three independent measurements.

\begin{tabular}{|lccc|}
\hline Substrate & $\begin{array}{c}\text { Bgl } \\
\text { (Units) }\end{array}$ & $\begin{array}{c}\text { Egl } \\
\text { (Units) }\end{array}$ & $\begin{array}{c}\text { XynA } \\
\text { (Units) }\end{array}$ \\
\hline Lichenan & $2600^{*}$ & $368^{*}$ & NM \\
CM-cellulose & NM & $45^{*}$ & NM \\
Oat spelt xylan & NM & NM & $316^{*}$ \\
Birch wood xylan & NM & NM & $228^{*}$ \\
AZCL $\beta$-glucan & $100 \dagger$ & $5 \dagger$ & NM \\
AZCL HE-cellulose & NM & $20 \dagger$ & NM \\
AZCL xylan & NM & $0 \cdot 05 \dagger$ & $234 \dagger$ \\
\hline
\end{tabular}

NM, not measurable.

* Unit defined as $1 \mu \mathrm{mol}$ reducing sugar $\min ^{-1}$ (mg purified enzyme $)^{-1}$.

†Unit defined as $1 \mathrm{OD}_{595}$ unit $\mathrm{min}^{-1}$ (mg purified enzyme $)^{-1}$.

et al., 1986) except for a single substitution of $T_{184}$ to $C_{184}$. The resulting amino acid substitution, $\mathrm{Ser}_{23}$ to $\mathrm{Pro}_{23}$, is located within the signal peptide and does not affect the sequence of the mature protein. The apparent molecular mas of $20.5 \mathrm{kDa}$ as calculated from the sequence and estimated by SDS-PAGE of the xylanase enzyme expressed in E. coli cells, agrees with the value reported for the PAP115 xylanase (data not shown). The purified product of $x y n A$ was active against oat spelt xylan and birch wood xylan but no activity against laminarin, lichenan or CM-cellulose could be detected (Table 2).

\section{Construction of mutants without $\beta$-glucanase and xylanase activity}

Transformation of DB104 with integrating plasmid pMW5 carrying the deleted eglS gene with the flanking sequences $(\Delta$ eglS102) yielded transformants with two different phenotypes: most of the transformants were $\mathrm{Cm}^{\mathrm{R}} \mathrm{EgIS}^{+}$but about $10 \%$ were found to be $\mathrm{Cm}^{\mathrm{R}}$, $\mathrm{EglS}^{-}$. The EglS ${ }^{-}$phenotype could not result from a single crossover event between homologous regions because the eglS gene would not be interrupted. Most likely the $\mathrm{EglS}^{-}$phenotype derives from a double crossover replacement between the homologous chromosomal region and concatemer of pMW5 (Stahl \& Ferrari, 1984). The plasmid phenotype is unstable because of flanking directly repeated DNA. To excise plasmid DNA, $\mathrm{Cm}^{\mathrm{R}}$ EglS ${ }^{-}$transformants were cultivated for about 10 generations in antibiotic-free medium. One cured $\mathrm{Cm}^{\mathrm{s}}$ clone, designated MW8, with a stable $\mathrm{EgIS}^{-}$phenotype was selected.

Transformation of MW8 with the integrative plasmid pMW4 carrying the deleted $b g / S$ gene yielded only $\mathrm{Cm}^{\mathbf{R}}$ $\mathrm{BglS}^{+}$clones. The $\mathrm{BglS}^{-}$phenotype was not detected. This result might be due to the size of the $1.2 \mathrm{~kb}$ deletion introduced in the $b g l T / b g l S$ region. Clones with the $\mathrm{Cm}^{\mathrm{s}}$ $\mathrm{BglS}^{-}$phenotype were obtained after cultivation in the absence of antibiotic selection and one of them, named 

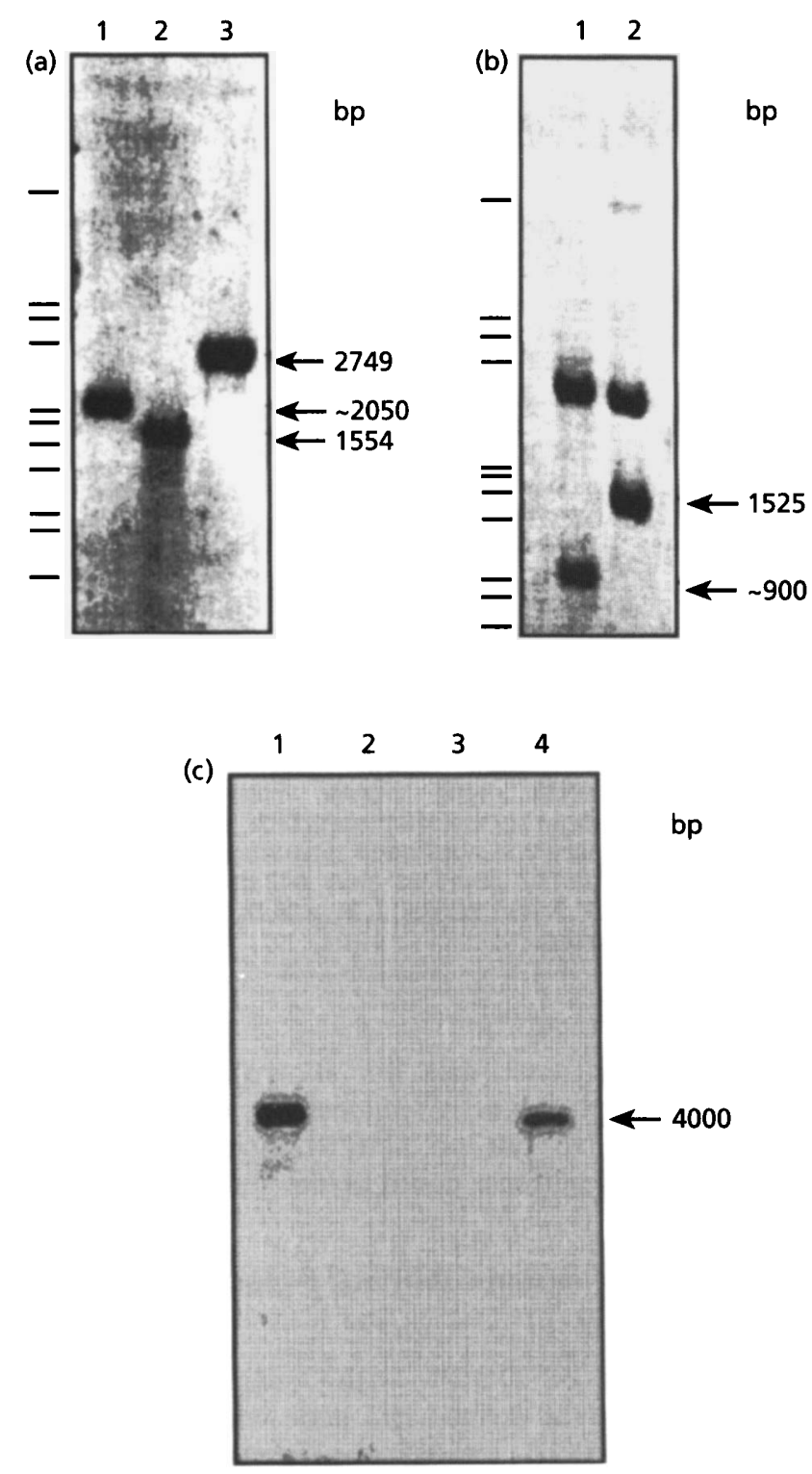

Fig. 2. Southern blot analysis of chromosomal DNAs from DB104 and strains harbouring $\Delta b g l$ and $\Delta e g l$ genes. (a) Hindlil/Sphl digest of chromosomal DNAs hybridized with the $0.8 \mathrm{~kb}$ EcoRV-Sphl fragment from pRB33 (bgl). Lanes: 1, MW9 with $\Delta b g / 55 ; 2$, MW10 with $\Delta b g / S R V ; 3$, DB104 with the entire $\mathrm{bg} / \mathrm{gene}$. The positions of size standards (EcoRl/Hindlll-digested 2) are indicated. Deletion $\Delta b g / S 55$ (MW9) is $669 \mathrm{bp}$, and $\triangle b g / S R V$ is 1195 bp. (b) Chromosomal DNAs digested with Pvull and hybridized with the left-hand $1645 \mathrm{bp}$ HindIII/EcoRI fragment from pRB36 (eg/). Lanes: 1 , MW10 with $\Delta$ eg/S102; 2 , DB104 with the entire egl gene. The positions of size standards ( $\lambda E$ coRI/HindIII) are indicated. The $3 \mathrm{~kb}$ fragment visible in both lanes, indicates a $3^{\prime}$ Pvull fragment harbouring or $X$ and the upstream sequence of eg/S. (c) EcoRI-digested DNAs from $B$. subtilis 168 (lane 1), YAC 12-5 (lane 2), YAC 15-37 (lane 3) and YAC 15-19 (lane 4) were probed with the amplified $760 \mathrm{bp}$ xynA fragment. Note: this picture has been electronically imaged.

MW10, was chosen for further studies. Another deletion within the $b g l S$ gene was introduced using integrative plasmid pMW3. The $\mathrm{Cm}^{\mathrm{R}} \mathrm{Bgl}^{-}$phenotype was not observed after transformation into MW8. However, after cultivation without selection pressure, stable $\mathrm{Cm}^{\mathrm{s}} \mathrm{Bgl}^{-}$ clones could be isolated. One of these was designated MW9. Southern hybridization verified that the transformed strains harbour the deleted $b g / S$ and $e g l S$ genes (Fig. 2).

Another strategy was used to construct strains deficient in xylanase activity. The central 382 bp Pst I-ScaI fragment isolated from the $x y n A$ gene was cloned into integrative plasmid pHV60, digested with appropriate restriction enzymes and used to transform strain MW10 (lacking cellulase and lichenase activity). $\mathrm{Cm}^{\mathrm{R}}$ clones were checked for deficiency in xylanase activity on AZCL-xylancontaining plates. Southern hybridization revealed that the xylanase-deficient strain MW15 contains two deleted copies of $x y n A$ on the chromosome (results not shown).

\section{Mutant strains with the $\beta$-galactosidase $\alpha$-complementation systems}

To use the versatile $\beta$-galactosidase $\alpha$-complementation system developed for $B$. subtilis (Haima et al., 1990) the lacZ $\triangle \mathrm{M} 15$ gene from 6GM15 was introduced by congression into strain MW10 ( $\left.\mathrm{Egl}^{-} \mathrm{Bgl}^{-}\right)$. The resulting strains MW11-MW13 would exhibit a blue phenotype on X-Gal agar plates if transformed by plasmid pHPS9 $(\operatorname{lac} Z \alpha)$, but only light blue colonies were detected after $2 \mathrm{~d}$ at $37^{\circ} \mathrm{C}$. Using MUG as substrate, $\beta$-galactosidaseproducing clones could be detected after $1 \mathrm{~d}$ at $37^{\circ} \mathrm{C}$.

To test the usefulness of the $\alpha$-complementation system for direct cloning of recombinants in $B$. subtilis, a cloning experiment with the 1,3-1,4- $\beta$-glucanase gene from $B$. amyloliquefaciens (bglA) was performed. A $3.6 \mathrm{~kb}$ EcoRI DNA fragment harbouring the $b g l A$ gene (Borriss et al., 1985) was ligated to EcoRI-cleaved pHPS9 DNA. The ligation mixture was used to transform competent MW12 cells, and transformants were selected on plates containing $\mathrm{Cm}, \mathrm{X}-\mathrm{Gal}$ and lichenan. After $2 \mathrm{~d}$, light blue and white $\mathrm{Cm}^{\mathrm{R}}$ colonies could be distinguished. Staining with Congo red revealed that only white colonies expressed $\beta$ glucanase activity on lichenan agar. As expected, the white clones contained recombinant plasmids with the 3.6 kb DNA fragment, whereas the blue clones contained only the religated vector pHPS9.

\section{Characterization of mutant strains}

Expression of $\beta$-glucan hydrolases was examined on agar plates supplemented with lichenan and CM-cellulose. Strain MW8, deficient in extracellular 1,4-endo- $\beta$-glucanase $(\Delta e g l S)$, did not hydrolyse CM-cellulose agar but was able to degrade lichenan. Double mutants harbouring $\Delta e g l S$ and $\Delta b g l S$ lacked 1,3-1,4- $\beta$-glucan hydrolysing activity, whereas strain MW14 with $\Delta b g / S 55$ hydrolysed CM-cellulose just like the parental strain DB104. In addition, MW14 was slightly active towards lichenan, suggesting that the $e g l S$ gene product is able to hydrolyse mixed linked $\beta$-glucans (Fig. 3). MW15 harbouring $\Delta e g l S$, $\Delta b g l S$ and $\Delta x y n A$ was not able to hydrolyse lichenan, CMcellulose or AZCL xylan. All strains were capable of 


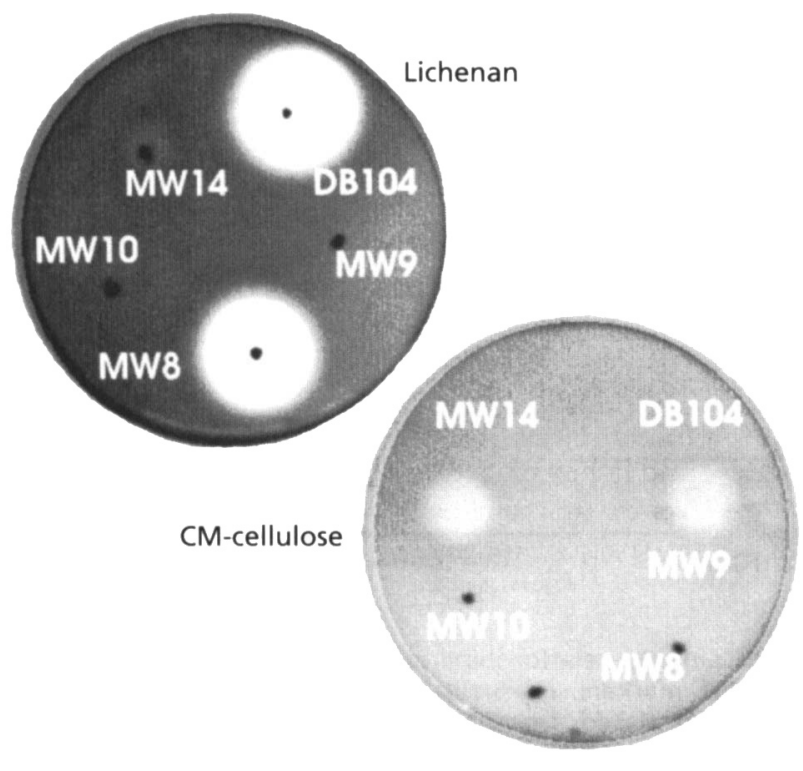

Fig. 3. Production of endoglucanases from mutant and wild type B. subtilis 168 . Relevant genotypes of mutant strains: $\Delta$ eg/S102 (MW8), $\Delta$ eg/S102 $\Delta$ bg/S55 (MW9), $\Delta$ eg/S102, $\triangle b g l b g / S R V$ (MW10) and $\Delta b g / S 55$ (MW14). Strains were spotted on a LB agar plate containing either CM-cellulose or lichenan. The plates were incubated at $37^{\circ} \mathrm{C}$ for $24 \mathrm{~h}$ and stained with Congo red. Note: this picture has been electronically imaged.

hydrolysing AZCL galactomannan but unable to degrade AZCL pachyman and AZCL xyloglucan (Table 3).

The presence of $\beta$-glucan hydrolysing enzymes was also checked by the zymogram technique (Fig. 4). Lichenase with an apparent molecular mass of $24 \mathrm{kDa}$ was detected in DB104 (wild type) and MW8 $(\Delta e g l S)$; cellulase isoenzymes with an apparent molecular mass of $34-36 \mathrm{~kb}$ were detected in DB104 and MW14 ( $\Delta b g l S)$. The apparent molecular mass of cellulase isoenzymes is much less than that deduced from the nucleotide sequence of the $B$. subtilis eglS gene. As in the case of the cloned eglS gene in E. coli, this might be due to processing and degradation of primary translation products. Lo et al. (1988) reported that the $52 \cdot 2 \mathrm{kDa}$ cellulase of $B$. subtilis PAP115 is cleaved progressively to a product of about $32 \mathrm{kDa}$ in its native host.

\section{bg/S, eg/S and xynA map in different regions of the B. subtilis chromosome}

With lysates prepared from $1 \mathrm{~A} 645$ (zif85: :Tn917) containing a silent $\operatorname{Tn} 917$ insertion at $342^{\circ}, 87.3 \%$ cotransduction of the $b g l S$ marker was observed. The $b g l S$ locus has previously been mapped to around $340^{\circ}$ on the B. subtilis chromosome (O'Kane et al., 1985; Borriss et al., 1986).

A high frequency of cotransduction of eglS was found with lysates containing a $\operatorname{Tn} 917$ insertion close to glt $A$ (map position $177^{\circ}$, Anagnostopoulos et al., 1993) prepared from 1A634 (zei82: : Tn917). To map the eglS gene more precisely, reference recipients of the Dedonder kit were transduced by PBS1 grown in MW10 ( $\Delta e g l S, \Delta b g l S)$, and the resulting recombinants were checked for linkage to the eglS locus. The results shown in Fig. 5 demonstrate linkage of eglS to thy $A\left(168^{\circ}\right.$, Tam \& Borriss, 1995) and glt $A\left(177^{\circ}\right)$, indicating a position of around $170^{\circ}$ on the circular chromosomal map of $B$. subtilis.

Cotransfer of $x y n A$ was also observed with lysates prepared from 1A634 (zei82: : Tn 917) using strain MW15 $(\Delta e g l \Delta b g l \Delta x y n A)$ as recipient. Of the primary $\mathrm{Em}^{\mathrm{R}}$ transductants, $27 \%$ exhibited the $\mathrm{XynA}^{+}$phenotype as checked by plating on AZCL xylan agar. Dedonder kit strains IA6 (thy $A$ ) and IA7 ( glt $A$ ) were used as recipients for donor lysates prepared from MW15. Six percent of Thy $\mathrm{A}^{+}$and $63 \%$ of $\mathrm{GltA}^{+}$transductants were $\mathrm{XynA}^{+}$, indicating cotransfer of the $x y n A$ marker. The genetic map compiled from data obtained by PBS1 transduction demonstrates that $\operatorname{egl} S$ and $x y n A$ are located within the thy $A-$ glt $A$ region at about $170^{\circ}$ and $175^{\circ}$ on the circular B. subtilis chromosome, respectively (Fig. 5).

In addition, a YAC library (Azevedo et al., 1993) was used to probe DNA fragments containing the eglS and $b g l S$ genes with an ordered collection of contiguous segments

\section{Table 3. Characterization of parental and mutant strains}

Strains were streaked onto LB agar plates containing different polysaccharides and grown for $2 \mathrm{~d}$. Hydrolysis of substrates is indicated by + . All strains degraded AZCL galactomannan but did not degrade AZCL pachyman or AZCL xyloglucan.

\begin{tabular}{|c|c|c|c|c|}
\hline Strain & Relevant genotype & Lichenan & CM-cellulose & Xylan \\
\hline DB104 & Wild type & + & + & + \\
\hline MW8 & $\Delta e g l S 102$ & + & - & + \\
\hline MW9 & $\Delta e g l S 102 \Delta b g l S 55$ & - & - & + \\
\hline MW10 & $\Delta e g l S 102 \Delta b g l T$ bglSR $V$ & - & - & + \\
\hline MW11 & $\Delta e g l S 102 \Delta b g l T$ bglSR $V$ & - & - & + \\
\hline MW12 & $\Delta e g l S 102 \Delta$ bglT bglSR V & - & - & + \\
\hline MW13 & $\Delta e g l S 102 \Delta b g l T$ bglSR $V$ & - & - & + \\
\hline MW14 & $\Delta$ bglS55 & $(+)$ & + & + \\
\hline MW15 & $\Delta e g l S 102 \Delta b g l T$ bglSR $V \Delta x y n A$ & - & - & - \\
\hline
\end{tabular}




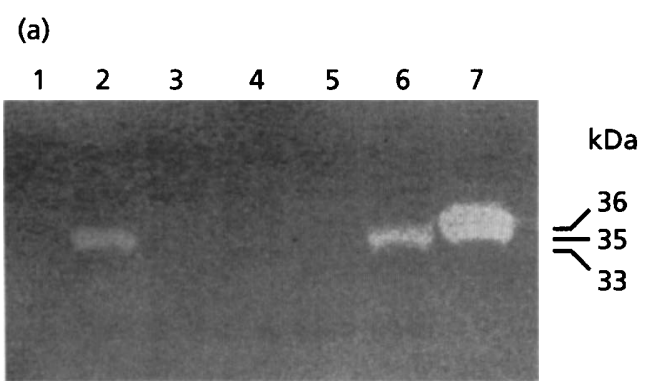

(b)

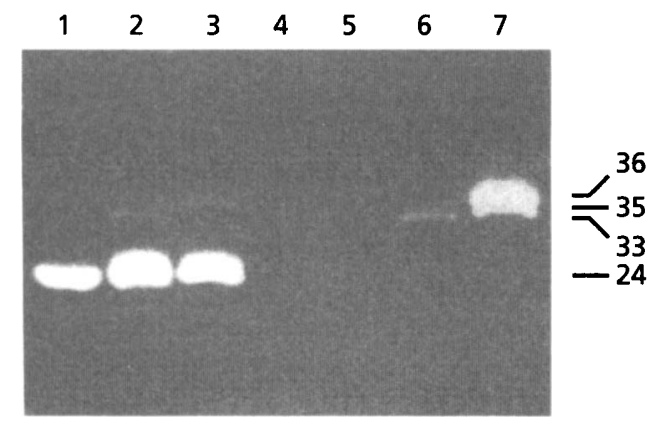

Fig. 4. Production of endoglucanases by mutant and wild-type B. subtilis 168 strains. Cells were cultured in LB medium at $37^{\circ} \mathrm{C}$ for $20 \mathrm{~h}$. Supernatants were concentrated by ultrafiltration and applied to SDS-polyacrylamide gels containing either lichenan or CM-cellulose. The gels were stained with Congo red. Apparent molecular masses are indicated. (a) SDS-PAGE gel with CM-cellulose. Lanes: $1,0.5 \mu \mathrm{g}$ purified 1,3-1,4-endo- $\beta$ glucanase; $2-6$, supernatants from DB104 (2), MW8 (3), MW9 (4), MW10 (5) and MW14 (6); 7, 0.6 $\mathrm{gg}$ purified protein from $E$. coli(pAG2) cells expressing $B$. subtilis 1,4-endo- $\beta$-glucanase. Cellulase isoenzymes with molecular masses ranging from 33 to $36 \mathrm{kDa}$ are visualized in lane 7 . Strains with the $\Delta$ eg/102 deletion (MW8, MW9 and MW10) were without detectable cellulase activity; purified lichenase (lane 1) did not degrade CM-cellulose. (b) SDS-PAGE gel with lichenan. Lanes were loaded as indicated in (a). Note that the supernatant of DB104 (lane 2) contains two lichenan hydrolysing activities with apparent molecular masses of $24 \mathrm{kDa}$ (lichenase) and $33 \mathrm{kDa}$ (cellulase). Lichenan is hydrolysed by purified $1,3-1,4-$-endo- $\beta$ glucanase (1) and 1,4-endo- $\beta$-glucanase (7). Strains harbouring either the intact $b g /$ gene (MW8) or the intact eg/ gene (MW14) are able to degrade mixed linked $\beta$-glucan. Note: this picture has been electronically imaged.

of the B. subtilis chromosome. The bglS gene hybridized with a $190 \mathrm{~kb}$ fragment carrying the but locus (designated clone 13-2), confirming previous results obtained by PBS1-mediated transduction. Interestingly, a gene designated $b g l A$ which encodes phospho- $\beta$-glucosidase hybridized in the region of overlap of YAC clones 13-2 and 11237 between but $\left(335^{\circ}\right)$ and gnt $\left(344^{\circ}\right)$ (Zhang \& Aronson, 1994).

Hybridizing signals from the $e g l S$ gene fragment were obtained with YAC clones 12-5 and 15-37 which form overlapping contigs of the $B$. subtilis chromosome from $165^{\circ}$ to $173^{\circ}$ and cover the thy $A, x y l$ and citB loci as well (Azevedo et al., 1993). Southern hybridization of eglS probed with EcoRI-digested DNA prepared from dif-

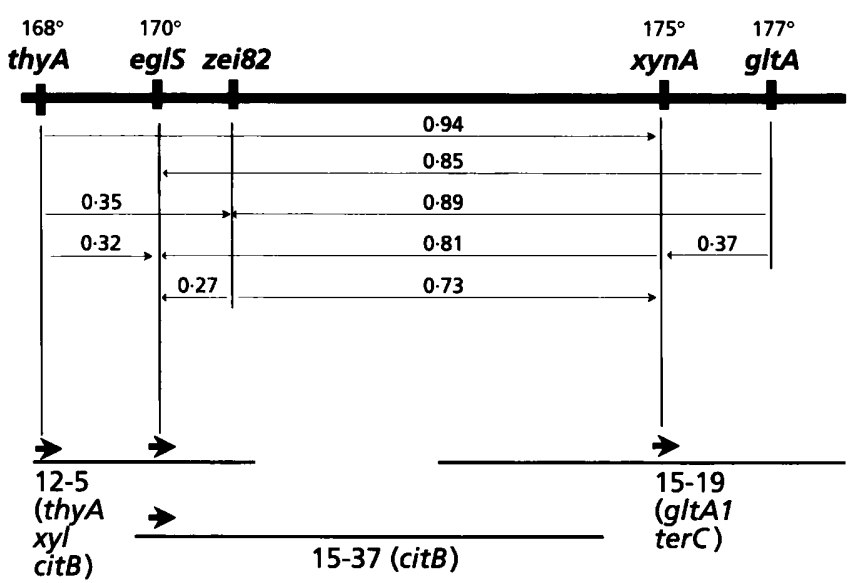

Fig. 5. Linkage relationships of thyA, eg/S, zei82::Tn917, xynA and gltA markers. Numerical values represent recombination indices calculated from at least two separate transduction experiments. Arrows point from the selected to the unselected marker. YAC clones 12-5, 15-37 and 15-19 correspond to the thy A-gltA region of the $B$. subtilis chromosome. Hybridization signals obtained for thyA, eg/S and xnyA with the YAC clones are indicated by bold arrows in the bottom part of the figure. Probing of the thyA gene fragments with DNA isolated from YAC $12-5$ is described in the accompanying paper (Tam \& Borriss, 1995).

ferent YACs verified the presence of eglS on overlapping contigs YAC 12-5 and 15-37 (Fig. 5).

Different results were obtained when the YAC library was used to probe for $x y n A$. EcoRI-digested DNA prepared from YAC 15-19 carrying glt $A$ but not YAC 12-5 and 1537 , which contain the eglS gene, hybridized with $x y n A$. Thus, the results obtained by genetic and physical mapping of eglS and $x y n A$ indicate that both genes are located within the region between thy $A\left(168^{\circ}\right)$ and glt $A$ $\left(177^{\circ}\right)$ which is covered by YAC contigs $12-5,15-37$ and 15-19. The map shows the gene order thy $A-e g l S-$ zei82-xynA-glt $A$ (Fig. 5). xyn $A$, which is located at about $175^{\circ}$, is clearly separated from eglS $\left(170^{\circ}\right)$ and the $x y l-x y n B$ cluster, which has been mapped at $168^{\circ}$ on the $B$. subtilis chromosome (Azevedo et al., 1993).

\section{DISCUSSION}

Numerous enzymes hydrolysing cellulose and different hemicelluloses as mixed linked $\beta$-glucan, xylan and galactomannan are secreted by $B$. subtilis (Table 3 ). Genes encoding 1,3-1,4- $\beta$-glucanase (bglS), 1,4- $\beta$-glucanase $(e g l S)$ and 1,4- $\beta$-xylanase $(x y n A)$ have been cloned previously from different $B$. subtilis strains, especially from industrial strain PAP115, and structurally characterized. We cloned the bglS, eglS and $x y n A$ genes from $B$. subtilis 168 . The sequences of the eglS and $x y n A$ genes from strain 168 were found to be virtually identical with the corresponding data reported for B. subtilis PAP115 (MacKay et al., 1986; Paice et al., 1986), suggesting that genes encoding extracellular enzymes are well conserved within B. subtilis strains. 
As reported by Murphy et al. (1984), bg/S encodes a protein with a molecular mass of $27338 \mathrm{Da}$. Processing of the 28 amino acid residue signal peptide results in a protein of about $24 \mathrm{kDa}$ (Yuuki et al., 1989). According to its primary sequence, the gene belongs to family 16 of glycosyl hydrolases formed by bacterial endo-1,3-1,4- $\beta$ glucanases (Henrissat \& Bairoch, 1993). The substrate specificity of endo-1,3-1,4- $\beta$-glucanase is restricted to mixed linked $\beta$-glucans such as lichenan or barley $\beta$ glucan. No other hemicellulosic or cellulosic substrates are hydrolysed (Table 2).

The B. subtilis eglS gene product (endo-1,4- $\beta$-glucanase) has been classified into family 5 of the glycosyl hydrolases (Henrissat, 1991). The enzyme is highly similar to other bacterial endo-1,4- $\beta$-glucanases and is able to hydrolyse $\mathrm{CM}$-cellulose and mixed linked $\beta$-glucans as well. The specific lichenan hydrolysing activity of $368 \mathrm{U}(\mathrm{mg}$ protein $)^{-1}$ was much less than the specific activity of $2600 \mathrm{U} \mathrm{mg}^{-1}$ determined for endo-1,3-1,4- $\beta$-glucanase, however. In addition, EgIS has a very low but detectable activity on AZCL xylan (Table 2).

Despite the weak xylan hydrolysing activity detected in EglS, the $x y n A$ gene product makes a major contribution to xylan-degrading activity in $B$. subtilis 168 . The enzyme shares more than $99 \%$ sequence identity with xylanases from B. subtilis PAP115 and B. circulans and has been grouped into family 11 comprising bacterial and fungal endo-1,4- $\beta$-xylanases (EC 3.2.1.8; Henrissat, 1991). The enzyme is active against oat spelt xylan and birchwood xylan virtually in the same range, but does not show any activity against the other substrates tested in this study (Table 2).

The gene replacement technique (Stahl \& Ferrari, 1984) was used to introduce permanent chromosomal deletions into the eglS and $b g l S$ structural genes in B. subtilis DB104. Strains MW10-12 carrying deletions in both genes $(\Delta e g / S$ $\Delta b g l S)$ were without detectable activity towards lichenan and $\mathrm{CM}$-cellulose, suggesting that the minor $\beta$-glucanases responsible for about $5-10 \%$ of total $1,3-1,4-\beta$-glucan hydrolysing activity found in $b g / S$ mutant strains of $B$. subtilis 168 (Borriss et al., 1986) represent processed products of the eglS gene. Biochemical analysis performed with the purified products of $b g l S$ and eglS suggests that the 1,3-1,4- $\beta$-glucanase degrades mixed linked $\beta$-glucans much faster than the 1,4- $\beta$-glucanase (see above). The activity of lichenase, BglS, was found to be seven times higher on lichenan and about 20 times higher on AZCL $\beta$ glucan than that of CMCase (EgIS; Table 2). Hence, both genes seem to be expressed to a similar level in B. subtilis, but differ in their capacity to hydrolyse mixed linked $\beta$ glucans.

Strain MW15 ( $\Delta$ bglS $\Delta$ eglS $\Delta x y n A$ ), constructed by disruption of the $x y n A$ gene in strain MW10, was devoid of activity towards lichenan, CM-cellulose and xylan (Table 3). Thus, our results obtained with the deletion mutants strongly suggest that EglS, BglS and $\mathrm{XynA}$ are the only enzymes involved in CM-cellulose, 1,3-1,4- $\beta$ glucan and xylan hydrolysis in B. subtilis.
The B. subtilis genes encoding cellulases and hemicellulases are possibly part of a global carbon catabolite repression regulon governed by an unidentified transacting factor (Krüger et al., 1993). Results obtained by PBS1 transduction and hybridization with contiguous DNA fragments cloned in a YAC library showed that the two genes encoding endo- $\beta$-glucan hydrolases are very distant from each other on the $B$. subtilis chromosome. The eglS gene was genetically mapped close to the thy $A$ locus at $170^{\circ}$. Southern hybridization performed with DNA from selected YAC clones confirmed the results of transduction analysis. The eglS gene was detected within the overlapping region of two contigs sharing the cit $B$ gene region. Similarly, the genetic position of $b \mathrm{glS}$ determined by PBS1-mediated transduction at about $340^{\circ}$, adjacent to but locus, was verified by hybridization of $b g l S$ DNA with YAC 13-2 containing the but operon.

The same combined genetic and physical approach has proven useful in mapping the $x y n A$ gene. Phage PBS1mediated transduction with strains harbouring deletions within $x y n A$ and the $\beta$-glucanase-encoding eglS and $b g l S$ genes places $x y n A$ at about $175^{\circ}$ close to the glt $A$ locus. This contradicts the findings of Roncero (1983) showing that $x y n A$ and $x y n B$ are clustered at the very distant map position of $48^{\circ}$ close to gua $B$.

A gene cluster with $x y l$ and $x y n C-x y n B$ genes was located near tby $A$ at $168^{\circ}$ (Hastrup, 1988). The $x y l$ gene was also physically mapped on YAC $12-5$ harbouring the thy $A$ gene (Azevedo et al., 1993). To clarify this situation we probed the cloned $x y n A$ fragment with the YAC library and with DNA from different contigs covering the region between thy $A$ and glt $A$. Only YAC 15-19 containing the glt $A$ locus hybridized with $x y n A$, confirming the results of our transduction mapping.

In summary, the three genes described in this study are distinct in structure, chromosomal location and substrate specificity of their respective products. We have been able to show that no other genes direct $\beta$-glucan and xylan degradation in B. subtilis. The mutants deficient in endo- $\beta$ glucanases and xylanase described here may well prove useful for secretion of heterologous $\beta$-glucan hydrolases and xylanases. In addition, direct cloning of genes encoding $\beta$-glucan hydrolases might be facilitated by using the $\alpha$-complementation system introduced into strain MW12.

\section{ACKNOWLEDGEMENTS}

The 247.1 library used for cloning of $b g / S$ and $e g l S$ genes was kindly provided by Harald Putzer. We gratefully acknowledge obtaining Bacillus kit strains, phage PBS1 and plasmid pHPS9 from the BGSC. Oligonucleotide primers used for amplification of $x y n A$ were obtained from Cordula Lindner and Michael Hecker. We thank Pascale Serror and Vladimir Sorokin for the opportunity to map $x y n$, egl and $b g l$ with the YAC library. We are especially grateful to Steffen Backert for performing pulse field gel electrophoresis and Martin Würtele for performing some of the PBS1-mediated transduction experiments. Jörg Stülke is thanked for communicating data prior to publication. We are very grateful to Edgar Schwartz, Michael Yudkin, Roy Doi and Bärbel Friedrich for critical reading of the manuscript. This 
work was supported by a grant from the Deutsche Forschungsgemeinschaft (SFB145-B10) to R. B.

\section{REFERENCES}

Anagnostopoulos, C., Piggot, P. J. \& Hoch, A. J. (1993). The genetic map of Bacillus subtilis. In Bacillus subtilis and Other GramPositive Bacteria: Biocbemistry, Physiology and Molecular Genetics, pp. 425-461. Edited by A. L. Sonenshein, J. A. Hoch \& R. Losick. Washington DC: American Society for Microbiology.

Anderson, M. A. \& Stone, B. A. (1975). A new substrate for investigating the specificity of $\beta$-glucan hydrolases. FEBS Lett 52, 202-207.

Azevedo, V., Alvarez, E., Zumstein, E., Damiani, G., Sgaramella, V., Ehrlich, S. D. \& Serror, P. (1993). An ordered collection of Bacillus subtilis DNA segments cloned in yeast artificial chromosomes. Proc Natl Acad Sci US A 90, 6047-6051.

Bolivar, F., Rodriguez, R., Green, P. J., Betlach, M., Heyneker, H. L., Boyer, H. W., Crosa, J. \& Falkow, S. (1977). Construction and characterization of new cloning vehicles. II. A multipurpose cloning system. Gene 2, 95-113.

Borriss, R., Suiss, K. H., SUiss, M., Manteuffel, R. \& Hofemeister, J. (1986). Mapping and properties of $b g l$ ( $\beta$-glucanase) mutants of Bacillus subtilis. J Gen Microbiol 132, 431-442.

Cornelis, P., Digneffe, C. \& Willemot, K. (1982). Cloning and expression of a Bacillus coagulans amylase gene in Escherichia coli. Mol \& Gen Genet 186, 507-511.

Dedonder, R. A., Lepesant, J., Lepesant-Kejzlarova, J., Billault, A., Steinmetz, M. \& Kunst, F. (1977). Construction of a kit of reference strains for rapid genetic mapping in Bacillus subtilis 168. Appl Environ Microbiol 33, 989-993.

Haima, P., van Sinderen, D., Bron, S. \& Venema, G. (1990). An improved $\beta$-galactosidase $\alpha$-complementation system for molecular cloning in Bacillus subtilis. Gene 93, 41-47.

Hastrup, S. (1988). Analysis of the Bacillus subtilis xylose regulon. In Genetics and Biotechnology of Bacilli, pp. 79-83. Edited by A. T. Ganesan \& J. A. Hoch. San Diego: Academic Press.

Henrissat, B. (1991). A classification of glycosyl hydrolases based on amino acid sequence similarities. Biochem J 280, 309-316.

Henrissat, B. \& Bairoch, A. (1993). New families in the classification of glycosyl hydrolases based on amino acid sequence similarities. Biochem J 293, 781-788.

Kawamura, F. \& Doi, R. H. (1984). Construction of a Bacillus subtilis double mutant deficient in extracellular alkaline and neutral proteases. J Bacteriol 160, 442-444.

Krüger, St., Stülke, J. \& Hecker, M. (1993). Catabolite repression of $\beta$-glucanase synthesis in Bacillus subtilis. J Gen Microbiol 139, 2047-2054.

Lederberg, E. M. \& Cohen, S. N. (1974). Transformation of Salmonella typhimurium by plasmid deoxyribonucleic acid. J Bacteriol 119, 1072-1074.

Lindner, C., Stulke, J., Krüger, St. \& Hecker, M. (1993). Induktion $\operatorname{der} \beta$-Glucanase-Synthese in Bacillus subtilis V.27. In Proceedings Erwin Riesch Symposium über Plasmide und Genregulation, Sellin, Rügen, Germany.

Lindner, C., Stülke, J. \& Hecker, M. (1994). Regulation of xylanolytic enzymes in Bacillus subtilis. Microbiology 140, 753-757.

Lo, A. C., MacKay, R. M., Seligy, V. L. \& Willick, G. C. (1988). Bacillus subtilis $\beta$-1,4-endoglucanase products from intact and truncated genes are secreted into the extracellular medium by Escherichia coli. Appl Environ Microbiol 54, 2287-2292.
MacKay, R. M., Lo, A., Willick, G., Zuker, M., Baird, S., Dove, M., Moranelli, F. \& Seligy, V. (1986). Structure of a Bacillus subtilis endoB-1,4-glucanase gene. Nucleic Acids Res 14, 9159-9170.

Mead, D. A., Szczwsna-Skorupa, E. \& Kemper, B. (1986). Singlestranded DNA 'blue' T7-promoter plasmids: a versatile tandem promoter system for cloning and protein engineering. Protein Eng 1, 67-74.

Michel, B., Niaudet, B. \& Ehrlich, S. D. (1983). Intermolecular recombination during transformation of Bacillus subtilis competent cells by monomeric and chimeric plasmids. Plasmid 10, 1-10.

Murphy, N., McConnell, D. J. M. \& Cantwell, B. A. (1984). The DNA sequence of the gene and genetic control sites for the excreted Bacillus subtilis enzyme $\beta$-glucanase. Nucleic Acids Res 12, 5355-5367.

O'Kane, C., Cantwell, B. A. \& McConnell, D. J. M. (1985). Mapping of the gene for endo- $\beta$-1,3-1,4-glucanase of Bacillus subtilis. FEMS Microbiol Lett 29, 135-139.

Olsen, O., Borriss, R., Simon, O. \& Thomsen, K. K. (1991). Hybrid Bacillus (1-3,1-4)- $\beta$-glucanases: engineering thermostable enzymes by construction of hybrid genes. Mol \& Gen Genet 225, 177-185.

Paice, M. G., Bourbonnais, R., Desrochers, M., Jurasek, L. \& Yaguchi, M. (1986). A xylanase gene from Bacillus subtilis: nucleotide sequence and comparison with B. pumilus gene. Arch Microbiol 144, 201-206.

Putzer, H. A., Brakhage, A. A. \& Grunberg-Manago, M. A. (1990). Independent genes for two threonyl-tRNA synthetases in Bacillus subtilis. J Bacteriol 172, 4593-4602.

Roncero, M. I. (1983). Genes controlling xylan utilization by Bacillus subtilis. $J$ Bacteriol 156, 257-263.

Saito, H. \& Miura, K. I. (1963). Preparation of transforming deoxyribonucleic acid by phenol treatment. Biochim Biophys Acta 72, 619-629.

Sanger, F., Nicklen, S. \& Coulson, A. R. (1977). DNA sequencing with chain-terminating inhibitors. Proc Natl Acad Sci USA 74, 5463-5467.

Shima, S., Igarashi, Y. \& Kodama, T. (1993). Purification and properties of two truncated endoglucanases produced in Escherichia coli harbouring Clostridium cellulolyticum endoglucanase gene celCCD. Appl Microbiol Biotechnol 38, 750-754.

Stahl, M. L. \& Ferrari, E. (1984). Replacement of the Bacillus subtilis subtilisin structural gene with an in vitro-derived deletion mutation. $J$ Bacteriol 158, 411-418.

Takahashi, M. \& Hashimoto, Y. (1963). Studies on bacterial xylanase. IV. On the nature of the crystalline xylanase of Bacillus subtilis G2. Hakko Kogaku Zasshi 41, 186-189.

Tam, Ng. H. \& Borriss, R. (1995). The thy $A$ gene from Bacillus subtilis exhibits extensive similarity with the phage $\phi 3 \mathrm{~T}$ thymidylate synthase gene. Microbiology 141, 291-297.

Thomson, J. A. (1993). Molecular biology of xylan degradation. FEM Microbiol Rev 104, 65-82.

Vandeyar, M. A. \& Zahler, S. A. (1986). Chromosomal insertions of Tn917 in Bacillus subtilis. J Bacteriol 167, 530-534.

Yuuki, T., Tezuka, H. \& Yabuchi, S. (1989). Purification and some properties of two enzymes from a $\beta$-glucanase hyperproducing strain, Bacillus subtilis HL-25. Agric Biol Chem 53, 2341-2346.

Zhang, Y. \& Aronson, A. (1994). A Bacillus subtilis bgl $A$ gene encoding phospho- $\beta$-glucosidase is inducible and closely linked to a NADH dehydrogenase-encoding gene. Gene 140, 85-90.

Received 13 July 1994; revised 5 September 1994; accepted 21 September 1994. 